\title{
¿QUÉ HACER CON EL CONTROL SOBRE LAS CUENTAS PÚBLICAS?
}

\author{
JUAN FERNANDO DURÁN ALBA \\ Profesor Titular de Derecho Constitucional \\ Universidad de Valladolid
}

SUMARIO

I. Introducción II. ¿Es posible articular debidamente la posición institucional de las instituciones fiscalizadoras? III. La difícil articulación de los controles técnicos y políticos. IV. La articulación territorial.

\section{INTRODUCCIÓN}

Realizar un diagnóstico sobre el estado de nuestro modelo de control externo de las cuentas públicas es una tarea que sobrepasa, con mucho, los límites de un trabajo como el que ahora se introduce. Además, incluso seleccionando muy precisamente los elementos que pueden ser objeto de examen, éste se encuentra ineludiblemente limitado por la aproximación escogida y la metodología seguida. El lector encontrará a lo largo de las siguientes páginas algunas reflexiones que tienen que ver, sustancialmente, con aspectos institucionales del control externo de las cuentas públicas. En su dimensión horizontal se tratan las difíciles relaciones entre la fiscalización técnica y el control político, los efectos que para la posición institucional de los órganos fiscalizadores ha tenido la «parlamentarización» del sistema y el aparente traslado al mismo de la lógica del Estado de partidos. En su dimensión vertical, serán objeto de algunas consideraciones determinados problemas que tienen que ver con un complejo sistema de control ampliamente descentralizado.

Algunos extremos transmitidos por los medios de comunicación parecen no dar pie, precisamente, al optimismo. Quizá, una de las noticias más traumáticas ha sido la desaparición de un órgano de control externo autonómico con las excusa de los duros ajustes presupuestarios acometidos para hacer frente la profunda crisis económica de los últimos años. En un contexto, no sólo de extraordinarias restricciones presupuestarias, sino de extrema atención hacia la gestión de los caudales 
públicos, no parece la mejor de las ideas que una de las víctimas de los recortes sea el encargado de fiscalizar el sector público. Se traslada así, seguramente de forma inconsciente, un perverso mensaje al ciudadano: la existencia de por lo menos parte del aparato institucional autonómico, con independencia de las relevantes funciones que asuma, es perfectamente contingente, incluso caprichosa.

Quienes están llamados a preservar la rectitud del modelo, comportándose con lealtad institucional, no siempre actúan desplegando la mejor pedagogía en sus maneras cotidianas. Hace tiempo, algunos responsables políticos, al ser interrogados por el retraso en la renovación, entre otros, de los órganos de control externo, con manifiesta ausencia del rubor, consideraban que la sintonía política, la falta de presión social y los intereses electorales justifican el incumplimiento de las normas sobre renovación, con retraso de varios años inclusive, sin que la situación sea parangonable a lo sucedido con el Tribunal Constitucional ${ }^{1}$.

Por su parte la jurisprudencia del Tribunal Constitucional se mantiene constante, dado el objeto de los asuntos llegados al alto tribunal, en su esfuerzo por determinar las competencias que le corresponden al Tribunal de Cuentas en relación con la existencia de órganos de control externo autonómicos $(\mathrm{OCEX})^{2}$. A pesar de ello, se advierten ciertas imprecisiones que dan lugar a algún interrogante. Uno de ellos es el sentido que ha de darse a la aparente dicotomía que existe en asegurar la supremacía fiscalizadora del órgano nacional para declarar, a continuación, que «el ámbito principal y preferente del ejercicio de su función fiscalizadora es la actividad financiera del Estado y del sector público estatal» ${ }^{3}$. Ello inmediatamente conduce a preguntarse si lo que parece una llamada a la autocontención es controlable en el caso de no apreciarse.

$\mathrm{O}$, en materia de enjuiciamiento contable, a la hora de resolver en favor del Tribunal de Cuentas el ejercicio exclusivo de la función de enjuiciamiento contable el Tribunal Constitucional parece haber dejado, más bien deslizado, un resquicio para la intervención de los órganos autonómicos en este particular (además de la eventual participación de éstos en la fase instructora de este tipo de procedimientos, por delegación del Tribunal de Cuentas). Así, cuando niega la competencia del órgano autonómico en la materia, el Tribunal Constitucional señala que la norma autonómica carece de cobertura constitucional y estatutaria en la materia (STC 187/1988, de 17 de octubre, FFJJ 3 y 5); la pregunta que surge evidentemente es: ¿cabe interpretar, a contrario, que si el correspondiente

1 «"Incumplir los plazos no es bueno, pero no hay presión social, hay buen ambiente en los consejos, las personas que están al frente de estas instituciones son técnicamente buenas y los dictámenes salen adelante sin problemas", explica el secretario de Organización del PSOE de Castilla y León, P.J. Muñoz. Vamos, que no es la situación del Constitucional. "Nada tiene que ver con ese embolado”, precisa un cargo del PP» («Las listas del 2011 tienen paralizada la renovación de los consejos institucionales», El Norte de Castilla, 6 de junio de 2010).

2 Biglino Campos, P.; «El control de cuentas: un contenido necesario de la reforma constitucional», Repensar la Constitución. Ideas para una reforma de la Constitución de 1978: reforma y comunicación dialógica. Parte primera (coords. T. Freixes Sanjuán y J. C. Gavara de CARA), CEPC, Madrid, 2018, p. 155.

3 STC 31/2010, de 28 de junio, FJ 34 (y resoluciones anteriores allí recogidas). 
Estatuto de Autonomía atribuyera funciones de enjuiciamiento al órgano autonómico sería constitucionalmente admisible? No me parece que pueda llegarse a esa conclusión pues el Tribunal Constitucional ha dejado expresamente señalado el carácter exclusivo y único del orden jurisdiccional en materia de enjuiciamiento contable, con la excepción, reiteradamente apuntada, de la participación de los órganos autonómicos en la fase instructora de los procedimientos de responsabilidad contable, siempre previa delegación del propio Tribunal de Cuentas en los términos previstos en su Ley Orgánica ${ }^{4}$.

\section{II. ¿ES POSIBLE ARTICULAR DEBIDAMENTE LA POSICIÓN INSTITUCIONAL DE LAS INSTITUCIONES FISCALIZADORAS?}

Resulta sumamente discutible trazar un paradigma común para todos los órganos de control externo existentes en nuestro país; no en términos absolutos pues, ya desde el punto de vista de su reconocimiento, el abanico de posibilidades transita desde la Constitución, los Estatutos de Autonomía y el mero reconocimiento legal en algunas CCAA, aunque este último plenamente convalidado por el Tribunal Constitucional al encontrar encaje en las potestades de autoorganización de aquéllas 5 . En este marco aparentemente heterogéneo sí es posible encontrar trazas comunes lo suficientemente relevantes como para advertir que un buen número de las disfuncionalidades de nuestro modelo de control externo de las cuentas públicas puede traer su causa de la indefinición de dos extremos: la dependencia parlamentaria de los órganos de control externo y las relaciones de supremacía y autonomía entre el órgano nacional y los autonómicos.

\section{A) Despolitizar la dependencia parlamentaria}

No parece que quebrar definitivamente la dependencia interorgánica, en abstracto, para vincular a los órganos de control con el Ejecutivo pudiera ser una solución viable si se quiere afrontar la cuestión en términos de control externo ${ }^{6}$. En términos históricos, el control político-parlamentario de las cuentas supone una superación de la desidia de la Cámara por, una vez consentidos los ingresos

4 Durán Alba, J. F.; «Las instituciones de autogobierno y otros órganos autonómicos ante el proceso de reforma estatutaria», La reforma de los Estatutos de Autonomía, Revista Jurídica de Castilla y León, 2003, p. 373.

5 STC 204/1992, de 26 de noviembre, FFJJ 3, 4 y 5. Qué duda cabe de que la ausencia de cobertura estatutaria simplifica enormemente las tentaciones de «liposucción» del aparato institucional autonómico que únicamente tiene que acudir al legislador en lugar de afrontar una penosa reforma estatutaria (así ha sucedido con la Sindicatura de Cuentas de Castilla-La Mancha, suprimida por la Ley de dicha Comunidad 1/2014, de 24 de abril).

6 Biglino CaMpos, P.; «Parlamento, presupuesto y Tribunal de Cuentas», Revista de las Cortes Generales, $\mathrm{n}^{\circ} 37,1996$, p. 35 . 
del Monarca, conocer cuál había sido su destino; y en este sentido, no deja de ser un hito que se lograra sustraer del control ejecutivo al órgano encargado de someter a escrutinio las cuentas públicas y que desempeñara esa actividad por cuenta de la Cámara ${ }^{7}$. Lo que quizá no se haya entendido en sus justos términos es que la relación entre la Cámara y el órgano de fiscalización no convierte a éste en un órgano parlamentario o en un mero agente de aquélla sino que en puridad busca asegurar su posición frente al resto del entramado institucional que, además, está llamado a ser fiscalizado ${ }^{8}$.

En el caso del Estado, la relación entre las Cortes Generales y el Tribunal de Cuentas presenta algunas fisuras. Así, la relación de dependencia entre ambos órganos abona el terreno para que la comparecencia parlamentaria en la que se presente y discuta el resultado de la fiscalización discurra por derroteros que se alejen de los criterios técnicos. Como se verá más adelante, en la base del riesgo se sitúa el hecho de que, aunque las relaciones interorgánicas debieran servir para colocar bajo la protección del «paraguas» parlamentario la actuación fiscalizadora, el Ejecutivo podría correr la tentación de apoyarse en la mayoría parlamentaria que lo sustenta para dificultar políticamente el ejercicio del control, tanto técnico (entorpeciéndolo desde la Cámara), como político. Desde luego no ayuda a mitigar esta situación el mecanismo de designación parlamentaria de los integrantes del órgano fiscalizador, que ha cristalizado en un sistema de cuotas al que se adhieren con entusiasmo periódico las fuerzas políticas sin distinción ideológica - siempre que cuenten con posibilidades de optar al reparto- y que ensombrece otras garantías de cualificación técnica o del estatus personal contenidas en la norma.

La situación es perceptiblemente más comprometida para los OCEX autonómicos desde el momento en que algunas leyes autonómicas buscan que la composición de la entidad fiscalizadora refleje la composición de la Cámara en términos de proporcionalidad ${ }^{9}$. No es mejor la situación desde el punto de vista de la autonomía territorial: las normas estatutarias, salvo excepciones muy puntuales, no proclaman la autonomía de órgano fiscalizador. En este sentido se mencionaba anteriormente la supresión de la Sindicatura de Cuentas de Castilla la Mancha; por traumática que pueda ser la medida, en otras ocasiones el legislador, con evidente desprecio hacia la posición de estos órganos ha intervenido

7 Estas cuestiones se encuentran más desarrolladas en: Durán AlbA, J. F.; «Hacia un modelo de relaciones entre los órganos de control externo y las Asambleas legislativas de las Comunidades Autónomas desde la lógica parlamentaria», Parlamento y control del gobierno (coord. por Francesc PAU I VAlL), Aranzadi, Pamplona, 1998, en particular pp. 401-404.

8 Biglino Campos, P.; «Parlamento, presupuesto y Tribunal de Cuentas», ob. cit., para el Tribunal de Cuentas (p. 38) y «La posición institucional de los órganos de control externo en los nuevos Estatutos de Autonomía», Pluralismo territorial y articulación del control externo de las cuentas públicas (dirs. P. Biglino CAMpos y J. F. Durán AlBA), Lex Nova, Valladolid, 2008, para los órganos autonómicos (p. 23).

9 Véanse, en este particular, las leyes reguladoras de los OCEX de Andalucía y Castilla y León (BigLiNO CAmpos, P.; «El control de cuentas: un contenido necesario de la reforma constitucional», ob. cit., p. 159). 
para menoscabar la autonomía presupuestaria, reglamentaria y de gobierno que debería corresponderles ${ }^{10}$; desprecio al que no ha sido ajeno el Ejecutivo invadiendo ámbitos propios del legislativo como son las retribuciones de los integrantes de la Cámara y de los órganos dependientes de las mismas ${ }^{11}$.

\section{B) Algunas amenazas hacia la autonomía en términos territoriales}

El ya celebérrimo informe CORA, que recoge las conclusiones de la Comisión para la Reforma de las Administraciones Públicas, elaboradas en el seno del Ministerio de Hacienda y Administraciones públicas en 2013 ha pretendido afectar de lleno al campo de la fiscalización de las cuentas públicas. En el apartado relativo a la Subcomisión de Duplicidades Administrativas enseguida se apunta a los órganos de fiscalización autonómicos, cuando se refleja que «en el caso de los OCEX, se da la paradoja de que el Tribunal de Cuentas del Estado puede también fiscalizar a la administración autonómica, incluso siguiendo mandatos del poder legislativo, lo que propicia la aparición de ineficiencias en la gestión de los medios públicos y una mala calidad de los resultados», todo ello sin acompañar el pliego acusatorio de prueba de cargo alguna que lo confirme ${ }^{12}$. A continuación, apelando a la satisfacción del interés público pero sin rastro de salvaguarda del principio de autonomía constitucionalmente consagrado se afirma que «[e]n los tres ámbitos, existen CC.AA. que carecen del organismo en cuestión, sin que, como se indica a continuación, se vea mermada la satisfacción del interés público» ${ }^{13}$.

10 Así, p. ej. la Ley 4/2013, de 19 de junio, por la que se modifica la organización y el funcionamiento y las instituciones propias de la Comunidad de Castilla y León. En ella, y con el argumento de la crisis económica, se suprime la secretaría general de la institución, que se refunde con la de otras instituciones autonómicas, con lo que se hace un flaco favor a la autonomía de gobierno del Consejo. Además, el número de consejeros se reduce de cinco a tres, se acorta el mandato que les corresponde (que pasa de seis a cuatro años, con lo que se facilita que coincida la mayoría parlamentaria que los ha designado) y se prevé que no se dediquen a la institución con carácter exclusivo, sino de manera parcial.

11 En esta misma CA, el Decreto-Ley 1/2012, de 16 de agosto, por el que se establecen medidas urgentes para garantizar la estabilidad presupuestaria establece con absoluto menoscabo hacia las atribuciones parlamentarias (consentido dócilmente, por cierto, en el trámite de convalidación) en su artículo 4, relativo a la paga extraordinaria del mes de diciembre o equivalente de 2012: «Igual reducción experimentarán las retribuciones de los vicepresidentes y secretarios de la Mesa de las Cortes de Castilla y León, los portavoces y demás cargos directivos de los grupos parlamentarios y los consejeros de los Consejos de Cuentas y Consultivo, sin que en ningún caso sus retribuciones puedan superar a las que resulten, tras la reducción, para los vicepresidentes y consejeros de la Junta de Castilla y León».

12 Un poco más adelante se vierten acusaciones aún más duras, tras deslizar que no se cuestiona la competencia de las CCAA para crear estos órganos: «La existencia de numerosos OCEX ha dado lugar a ineficiencias como el bajo rendimiento de los recursos destinados a los mismos, la heterogeneidad en las estructuras, composición y resultados de sus funciones, así como la duplicidad en la rendición de cuentas de las Entidades Locales al Tribunal de Cuentas y al órgano autonómico» (las cursivas pertenecen a este trabajo).

13 Comisión para la Reforma de las Administraciones Públicas: Reforma de las Administraciones Públicas, Ministerios de Presidencia y de Hacienda, Madrid, 2013, p. 100. 
Con la finalidad de evitar duplicidades, se llegaba a plantear que las funciones de fiscalización realizadas por las instituciones de las CCAA fueran asumidas por el Tribunal de Cuentas a través de las correspondientes Secciones Territoriales que habrían de crearse ${ }^{14}$. La propuesta suscitó la reacción de la Organización Europea de las Instituciones Regionales de Control Externo del Sector Público (EURORAI) que, en una declaración específica sobre el asunto, subrayaba «la importancia de un control externo del sector público fuerte y eficaz, ejercido in situ por entidades regionales, públicas e independientes» ${ }^{15}$, sobre todo en tiempos de recesión económica general y de recortes presupuestarios.

\section{LA DIFÍCIL ARTICULACIÓN DE LOS CONTROLES TÉCNICOS Y POLÍTICOS}

A pesar de la más perceptible —e intensa- vinculación de los órganos fiscalizadores de las cuentas con la cláusula Estado de Derecho, por cuanto su función parece indefectiblemente asociada a la verificación de que la ejecución del gasto en el sector público se realiza con sometimiento a la legalidad, dicha perspectiva es manifiestamente insuficiente para comprender en sus justos términos la posición institucional de este tipo de órganos. Para una más adecuada intelección del modelo es preciso distanciarse de un examen aislado del órgano y su marco funcional para combinarlo con las relaciones que se establecen entre éste y el destinatario último de sus informes. En este contexto, la construcción constitucional y estatutaria —o legal, allí donde no se ha considerado necesario elevar el rango de la norma que prevé la existencia del OCEX - aboca a que el destino lógico y natural de los informes de fiscalización sean las Cámaras parlamentarias. Desde el momento en que, no ya sólo los ingresos sino también el gasto público está «consentido» por la Asamblea, a ésta cumple pedir cuenta del empleo de los fondos públicos ${ }^{16}$. Es aquí, pues, donde las instituciones fiscalizadoras cumplen una función de primer orden, posibilitando el posterior

14 «se propone que sea el Tribunal de Cuentas el órgano de fiscalización de la Administración autonómica, al objeto de racionalizar, optimizando los recursos existentes, el sistema de control externo de las CC.AA., para lo que se crearían 12 Secciones Territoriales (correspondientes a las CC.AA que cuentan en la actualidad con OCEX, menos Madrid, por ser ésta la ciudad sede del Tribunal de Cuentas)». «Esta medida permitiría a las CC.AA. que cuenten con dichos OCEX poder prescindir de los mismos, y ahorrar el presupuesto anual dedicado a su sostenimiento».

15 EURORAI, en su calidad de asociación de órganos públicos de control externo, cuenta con más de 80 miembros procedentes de 16 países europeos. El texto de la declaración, aprobada en el VIII Congreso y Asamblea General de la asociación, celebrados en Halle (Alemania), del 17 al 18 de octubre de 2013, aparece en http://www.eurorai.org/eurorai/eurorai_es.nsf/titulares/declaracion_eurorai/\$file/Declaraci\%C3\%B3n\%20 de\%20EURORAI2.pdf (último acceso: 07/03/2018).

16 En palabras del propio GLADSTONE: «es indiscutiblemente asunto de la Cámara de los Comunes ser responsable del acometimiento de todo gasto público, y es también su deber seguir el empleo de los caudales levantados por la vía de los impuestos y pedir cuentas de ellos... hasta el último céntimo» (la cita se ha 
control parlamentario - político- mediante la previa fiscalización — técnica- de las cuentas públicas.

En un sistema parlamentario fuertemente penetrado por la lógica del Estado de partidos, sin embargo, la vieja relación dialéctica entre el poder ejecutivo y el poder legislativo ha sido sustituida por la querella política entre mayoría y minoría parlamentaria. Y la querella política va a alcanzar de lleno al órgano técnico en una realidad política en la que, sus actores, no siempre se comportan con lealtad y responsabilidad institucional. El fiscalizado mirará con sempiterna desconfianza al fiscalizador, ya que el resultado del escrutinio de las cuentas puede llevar aparejadas consecuencias, no sólo en términos políticos para los responsables de los órganos examinados, sino de naturaleza bien distinta para quien maneja fondos públicos, pues del desconocimiento del Derecho cabe deducir, en su caso, responsabilidad contable (ventilada ante el Tribunal de Cuentas, único en este orden, y en cuyos procesos de enjuiciamiento los OCEX autonómicos únicamente pueden llevar a cabo la instrucción previa delegación del órgano nacional) sin perjuicio de la responsabilidad civil o penal.

En la intención de conjurar estos posibles riesgos posiblemente se encuentre la tendencia seguida por los controlados de sujetar - y aún controlar-a los controladores ${ }^{17}$. A pesar de ello, no deja de sorprender la abierta hostilidad con la que se acogen en ocasiones los informes de fiscalización, aun cuando las observaciones que se contengan en los mismos no impliquen reconocer prácticas contra legem, sino críticas de carácter operativo ${ }^{18}$. La hostilidad no es ni mucho menos inocua, pues en no pocas ocasiones se traduce en la deslegitimación pública de la función fiscalizadora por parte de responsables políticos ${ }^{19}$.

No hace falta desplegar una imaginación desbordante para presumir lo que puede suceder si, quien recibe con desagrado la fiscalización, se apoya en la mayoría parlamentaria para censurar al controlador. Entonces, el procedimiento parlamentario de examen de los informes y memorias, según viene conformado por los Reglamentos y normas supletorias de las Cámaras, se convierte en lugar propicio

tomado por ToDD, A.; El gobierno parlamentario en Inglaterra, La España Moderna-Biblioteca de Legislación y Jurisprudencia, Madrid, año XII, c. 1914, p. 304, t. II).

17 Biglino Campos, P.; «El control de cuentas: un contenido necesario de la reforma constitucional», ob. cit., p. 151.

18 Para una referencia más exhaustiva sobre el destino parlamentario de los informes de fiscalización: Durán Alba, J. F.; «Vae Victis! La tramitación parlamentaria de los informes de los órganos de control externo de las cuentas públicas», Corts. Anuario de derecho parlamentario, no 20, 2008, págs. 67-89.

19 Como muestra puede leerse el siguiente titular «El Ejecutivo tilda el informe de «parcial» porque no incluye sus alegaciones»; (El Norte de Castilla, 5 de agosto de 2006); el titular presenta una noticia en la que se recogen afirmaciones sorprendentes: «la Junta de Castilla y León rechazó ayer, a través de un comunicado, el contenido del Informe de Fiscalización del Consejo de Cuentas, que tildó de «muy parcial e incompleto» y donde hay «conceptos que no se utilizan como debe ser». Al hilo de esto, [...], indicó que «faltan unos documentos preceptivos de acuerdo con la ley, como las alegaciones formuladas por la Junta y la resolución de esas alegaciones». En este sentido, manifestó que «es el Consejo el que debe explicar si tales alegaciones son aceptadas o no» $[\ldots]$... 
para invertir los términos de la relación de control y que quien resulte fiscalizado sea el órgano de control externo (principalmente su Presidente en condición de compareciente en la Cámara). Posiblemente uno de los ejemplos más señalado lo constituya la Resolución del Parlamento de Canarias, de 22 de abril de 1997, cuando se acuerda: «Encarecer a la Audiencia de Cuentas a que en sus informes como organismo de control externo, según definición de su ley de creación, aplique criterios técnicos rigurosos y muestre un exquisito respeto a las competencias de los diferentes órganos institucionales» ${ }^{20}$.

Por supuesto, la crítica formulada únicamente es posible cuando el órgano técnico actúe con un sometimiento escrupuloso al rigor técnico huyendo de la arbitrariedad, tanto en la determinación de los sujetos objeto de fiscalización en el caso de los informes específicos- como en contenido de los informes y observaciones realizadas ${ }^{21}$. En este sentido, resulta esencial no menoscabar la legitimidad de ejercicio como elemento esencial para configurar la naturaleza de estos órganos: un órgano de control externo será un órgano esencialmente técnico, con independencia del procedimiento de designación de sus miembros, si ajusta su actuación a criterios técnicos, objetivos y no de discrecionalidad o de oportunidad. Si bien la norma jurídica ofrece un elevado margen de certeza como elemento de contraste para determinar la adecuación a la misma de determinadas conductas, puede no suceder lo mismo (o no por lo menos con igual intensidad) cuanto se tratan de fiscalizar el cumplimiento de criterios de gestión operativa (la eficacia, eficiencia y economía).

Ciertamente, el control externo de las cuentas públicas no es sólo control de legalidad ${ }^{22}$ y en las sociedades contemporáneas el control operativo adquiere paulatinamente una mayor importancia junto con criterios de buena gestión y transparencia. Considero que sin un cambio de perspectiva en la percepción que del fiscalizado debe tener del fiscalizador, esto es, como un «cooperador necesario» en la consecución de las «buenas prácticas» económicas previamente consensuadas

20 Resolución, de 22 de abril de 1997, de la Presidencia, por la que se ordena la publicación de la Resolución adoptada sobre el Informe de la Audiencia de Cuentas de Canarias de Fiscalización de la Cuenta General de la Administración de la Comunidad Autónoma Canaria, correspondiente al ejercicio 1993, y el Informe de Fiscalización de las Sociedades Mercantiles pertenecientes a las Administración de la CA de Canarias, ejercicio 1993, en el Boletín Oficial de Canarias, de 16 de mayo de 1997.

21 El riesgo de extralimitación funcional, incluyendo valoraciones en los informes no estrictamente técnicas o sustituyendo a la Administración en la elección de sus prioridades de actuación ha sido advertido por VALLÈs, F.; «La garantía constitucional del ejercicio independiente del control externo del gasto público», Auditoría Pública, $\mathrm{n}^{\circ} 28$, enero 2003, p. 78-79.

22 Algunas propuestas abogan, incluso, por destinar el Tribunal de Cuentas a la auditoría operativa y dejar el control de legalidad radicado esencialmente en el control interno: BALLART, X.; « ¿Se puede cambiar el Tribunal de Cuentas?», El País, 1 de abril de 2013, disponible en: https:/elpais.com/elpais/2013/03/22/ opinion/1363948300_138055.html (último acceso: 08/03/2018). Con menor carga drástica, pero a favor de incrementar las auditorías operativas en detrimento de los controles de regularidad formal, MARTínEz MARTí, G. y MuÑoz SAN Román, E.; «Doce propuestas de mejora y una desiderata desesperada sobre la eficacia y eficiencia de los Órganos de Control Externo (OCEX)», Auditoría Pública, n 69, 2017, p. 60. 
es sumamente difícil conseguir la «conciencia pública de control» a que se refiere la Declaración de Pamplona de 2006, adoptada por la Conferencia de Presidentes de los $\mathrm{OCEX}^{23}$.

\section{ARTICULACIÓN TERRITORIAL}

\section{A) ¿El fin de la interpretación conforme sobre la articulación funcional? (la STC 89/2012, de 7 de mayo)}

Para articular debidamente la fiscalización externa de las cuentas públicas en un Estado territorialmente complejo resulta imprescindible no perder de vista, a modo de guía, la perspectiva de que la cuestión se sitúa en términos de concurrencia funcional sobre ámbitos territoriales que gozan de autonomía constitucionalmente reconocida ex artículo $137 \mathrm{CE}^{24}$. Concurrencia que, en el caso del sector público autonómico, trae su causa de que la propia Constitución, en su artículo 153, letra d), reserva - y preserva, aunque no en régimen de exclusividad- el control «económico y presupuestario» de las CCAA al Tribunal de Cuentas. Concurrencia, en fin, que, aunque pueda resultar ocioso recordarlo, no sólo se predica de los entes territoriales que cuentan con órganos de control externo (Estado y CCAA), pues en el caso de los entes locales, cuya autonomía tiene un carácter bifronte respecto de ambos (tempranamente afirmado por el Tribunal Constitucional en la STC 84/1982, de 23 de diciembre, FJ 4), el sector público local es objeto de la fiscalización estatal y autonómica.

Como ha quedado puesto de manifiesto, la intervención del Tribunal Constitucional en esta materia, en su mayor parte, se ha dirigido a determinar la posición funcional del Tribunal de Cuentas más que a detenerse en precisar cuáles son las relaciones constitucionales entre éste y los $\mathrm{OCEX}^{25}$. Muy desde el comienzo se ha evitado que se desplazara al órgano estatal a través de una lectura ad pedem liteae

23 Aborda exhaustivamente el contenido de la misma Jiménez Rius, P.; «La Declaración de Pamplona: una nueva etapa en el control externo de los fondos públicos en España», Auditoría Pública, n 41,2007 , pp. 31-42.

24 El contenido y alcance de esta concurrencia funcional, que impide el desplazamiento del órgano estatal una vez que la correspondiente comunidad autónoma se ha pertrechado institucionalmente en este ámbito, se ha analizado con mayor detenimiento en: DuRÁN ALBA, J.F.; «La doctrina de la «concurrencia funcional» en materia fiscalizadora y de la «exclusividad jurisdiccional» en materia de enjuiciamiento contable (comentario a la jurisprudencia del Tribunal Constitucional sobre el control externo de las cuentas públicas)», Estudios de Derecho Financiero y Tributario en homenaje al Profesor Rafael Calvo Ortega (coords. I. MARTín DéGano, G. Menéndez García y A. Vaquera García), Lex Nova, Valladolid, 2005, pp. 2451-2465 (t. II).

Por lo demás, la concurrencia funcional no acontece en todos los ámbitos institucionales, pues en otros supuestos, como el de la función consultiva, la creación del órgano autonómico sí provoca el desplazamiento funcional del Consejo de Estado (en los términos de la STC 204/1992, de 23 de diciembre).

25 Biglino CAmpos, P.; «El control de cuentas: un contenido necesario de la reforma constitucional», ob. cit., p. 155 . 
- pero absurda- de los artículos 136 y 153 CE que, en términos funcionales, reservara para el Tribunal de Cuentas una fiscalización del sector público en términos económicos pero no financieros ${ }^{26}$. Sin embargo, el Tribunal Constitucional se ha negado a admitir que pudiera privarse de naturaleza financiera a dicho control, en lo que pretendía ser una artificiosa distinción —además de poco sutil, por cierto- entre control de la gestión económica de las CCAA (el estrictamente previsto en la Norma fundamental) y control financiero de la gestión (que, aparentemente introducido ex novo por la ley, no resultaría compatible con la Constitución a juicio del recurrente), pues dicha naturaleza financiera se deduce perfectamente del propio artículo $136 \mathrm{CE}$ y de la ley orgánica que lo desarrolla ${ }^{27}$. El celo por preservar el propio ámbito competencial, también en materia de fiscalización de las cuentas públicas, ha conducido a impugnar ante el Tribunal Constitucional las normas que se limitaban a señalar la intervención del órgano de control externo conectado institucionalmente con el legislador concernido. Aunque sin exceso de despliegue argumental, el Tribunal venía considerando que las previsiones legales controvertidas en modo alguno podían interpretarse como limitativas a la intervención de los demás órganos de control, en su caso competentes. Así se resolvieron las impugnaciones siguientes: Artículo 23.3 de la Ley estatal 3/1993, de 22 de marzo, básica de las Cámaras Oficiales de Comercio, Industria y Navegación ${ }^{28}$; Artículos 5, letra b), y 9.1 de la Ley del Parlamento de Cataluña 6/1984, de 5 de marzo, de la Sindicatura de Cuentas ${ }^{29}$; Artículos 2, letra b), 20.1, letra b), 25.2 y

26 Los postulantes de la tesis entendían que el artículo 20 del Proyecto de Ley Orgánica de Armonización del Proceso Autonómico innovaba indebidamente el alcance de la fiscalización del sector público que constitucionalmente se reserva exclusivamente al escrutinio de la gestión económica (el precepto controvertido disponía que: «El Tribunal de Cuentas, órgano supremo de control externo de la gestión económica y financiera del sector público, establecerá Secciones Territoriales para el ejercicio de las funciones que le asigna su Ley Orgánica en el ámbito de cada Comunidad Autónoma»; la cursiva es pertenece a este trabajo).

27 O lo que es lo mismo, más bien, lo que se deduce del tenor de los preceptos constitucionales con respecto del Tribunal de Cuentas es que resulta: «función propia del mismo, la fiscalización externa, permanente y consuntiva de la actividad económico-financiera del sector público» (STC 76/1983, de 5 de agosto, FJ 25). En su voto particular concurrente a la STC 190/2000, de 13 de julio, el Magistrado Rafael de Mendizábal Allende recoge con mayor amplitud el significado de esta doctrina al afirmar que: «la 'actividad económica' de las Administraciones públicas afecta por una centenaria tradición a toda la vida patrimonial de las mismas, en cuanto implica la gestión de las Haciendas Públicas, incluyendo en consecuencia su aspecto presupuestario. Así lo ponen de manifiesto muchas normas de nuestro ordenamiento, donde se han regulado o se regulan bajo el mismo epígrafe y en un bloque conjunto las dos vertientes esenciales -ingresos y gastos-con el gozne entre ambos que significan los presupuestos, como ocurría en la venerable Ley de Administración y Contabilidad de la Hacienda Pública de 1 de julio de 1911, vigente durante dos tercios de siglo hasta 1977. Y así sucede también con el Título VII, bajo el epígrafe 'Economía y Hacienda', en la propia Constitución» (las cursivas son pertenecen a este trabajo).

28 El precepto de la ley (ya derogada) disponía: «En todo caso, las liquidaciones de los presupuestos de las Cámaras y del Consejo Superior referentes al Plan Cameral de Promoción de Exportaciones serán objeto de fiscalización por el Tribunal de Cuentas». El recurso de inconstitucionalidad fue resuelto por la STC 206/2001, de 22 de octubre, FJ 13.

29 En este caso, las disposiciones controvertidas de la ley catalana (igualmente ya derogada) preveían: que las corporaciones locales y sus organismos autónomos integraban a los efectos de la ley el sector público de Cataluña [artículo 5, letra b), de la ley] y la rendición de cuentas de las corporaciones locales radicadas en 
28 y de la Ley del Parlamento de Galicia 6/1985, de 24 de junio, del Consejo de Cuentas $^{30}$; Apartado 14 de la Orden del Ministerio de Industria, Comercio y Turismo de 16 de julio de 1992 sobre medidas de adaptación a la competencia internacional y diversificación de zonas con implantación de industria textil-confección ${ }^{31}$. Ha de indicarse que, en este caso, el Tribunal Constitucional resolvió el asunto mediante el expediente de vincular la atribución de la fiscalización controvertida con el carácter supremo del Tribunal de Cuentas, aunque deslizando que la supremacía no implica que sea el único órgano de control, lo que a contrario implica dejar a salvo la existencia de los órganos autonómicos ${ }^{32}$. A fortiori bien puede añadirse que es discutible que en una norma estatal se pudieran atribuir de forma expresa funciones a un órgano autonómico, más allá de incluir alguna reserva del tipo «sin perjuicio de las funciones que correspondan a los órganos autonómicos de fiscalización externa de las cuentas públicas»; Apartado 15 de la Orden del Ministerio de Industria y Energía de 6 de febrero de 1997, por la que se aprueban las bases reguladoras de la concesión de subvenciones en el marco del Plan de ahorro y eficiencia energética para el período 1997-1999 y se convocan las del ejercicio $1997^{33}$.

Así pues, la tesis del Tribunal Constitucional parecía mantenerse constante, sintetizándose en que no existe lesión de la autonomía constitucionalmente garantizada a las CCAA derivada del hecho de que la ley estatal atribuya la fiscalización de un determinado ámbito de la actividad económica autonómica al

la comunidad catalana ante la Sindicatura de Cuentas (artículo 9.1). La impugnación quedó resuelta por la STC 187/1988, de 17 de octubre.

30 Respecto de los artículos 2, letra b, y 25.2, el problema era idéntico al suscitado en la ley catalana, mientras que los artículos 20.1, letra b) y 28 de la norma cuestionada se refieren al contenido del informe anual de fiscalización del órgano gallego, que alcanza al cumplimiento de las previsiones y de la ejecución de los presupuestos de los entes locales, y a las multas coercitivas por falta de colaboración y que pueden recaer sobre autoridades locales, respectivamente. El recurso de inconstitucionalidad fue resuelto por la STC 18/1991, de 31 de enero.

31 «El beneficiario de la subvención estará obligado a mostrar los documentos que se soliciten en el plazo que se le indique y facilitar las comprobaciones encaminadas a garantizar la correcta realización de la actuación subvencionada. Asimismo, quedará sometido a las actividades de control financiero que corresponden a la Intervención General de la Administración del Estado y a las previstas en la legislación del Tribunal de Cuentas» (las cursivas son pertenecen a este trabajo).

32 STC 190/2000, de 13 de julio, FJ 11,h). El argumento se desarrolla en el voto particular del Magistrado De Mendizábal Allende quien hace hincapié en que la norma del estado no excluye sino que añade instrumentos de fiscalización: «el art. 14 de la Orden Ministerial en entredicho no se inmiscuye en el ámbito de competencias de la Comunidad Autónoma de Cataluña ni menoscaba las de su Sindicatura de Cuentas. La coexistencia de funciones neta y meramente fiscalizadoras en manos de aquélla y del Tribunal es, en lenguaje aritmético, una suma y no una resta».

33 «El beneficiario de la subvención estará obligado a presentar los documentos que se soliciten por la Secretaría de Estado de Energía y Recursos Minerales, en el plazo que se le indique, y a facilitar las comprobaciones encaminadas a garantizar la correcta realización de la actuación subvencionada. Asimismo, quedará sometido a las actividades de control financiero que corresponden a la Intervención General de la Administración del Estado y a las previstas en la legislación del Tribunal de Cuentas» (las cursivas pertenecen a este trabajo). Resuelto en idénticos términos que el anterior asunto por la STC 98/2001, de 5 de abril, FJ $8, \mathrm{k})$. 
Tribunal de Cuentas del Estado. Y no hay lesión porque dicha atribución no puede entenderse por sí misma excluyente del control encomendado, en su caso, al órgano autonómico de control externo; contrario sensu, por lo tanto, la lesión nacería desde el momento en que la norma estatal sí excluyera expresamente - $\mathrm{O}$ así pudiera entenderse- la fiscalización autonómica ${ }^{34}$. Desde la perspectiva inversa, la cuestión se ha planteado al atribuir las normas autonómicas la fiscalización de las corporaciones locales al correspondiente órgano de la Comunidad. La solución ha sido la misma, esta atribución no puede entenderse por sí misma contraria a la Constitución desde el momento en que en la misma no se contiene una expresa exclusión a la intervención del Tribunal de Cuentas ${ }^{35}$.

Nada cabe reprochar, a mi juicio, a la interpretación conforme que venía realizando el Máximo intérprete de la Constitución sin que, de lo expuesto, quepa inferir ni mucho menos que se habían traspasado los límites que, en la propia doctrina del Órgano de garantías constitucionales, impiden que se vaya más allá de la literalidad de la norma controvertida «conforme se pueda deducir 'de modo natural y no forzado' del tenor literal del precepto, sin afectación de la seguridad jurídica» (STC 185/2014, de 6 de noviembre, FJ 7). No obstante, con posterioridad y, hasta la fecha en único pronunciamiento, el Tribunal parece apartarse de la ratio decidendi anterior. Con ocasión de impugnarse, por parte del Gobierno catalán mediante conflicto positivo de competencias, la Resolución, de 13 de marzo de 2008, del Instituto Nacional de las Artes Escénicas y de la Música (INAEM) por la que se convocan ayudas para el año 2008 dentro del programa de espacios escénicos de nueva generación, se reprochaba que la previsión contenida en el apartado duodécimo vulnera las competencias del recurrente, al establecer actuaciones de comprobación del Tribunal de Cuentas «obviando los órganos de control propios de que dispone la Comunidad Autónoma de Cataluña» ${ }^{36}$. Así las cosas, el Tribunal, con una economía argumental propia de épocas de ajustes presupuestarios se limita a acoger las razones del recurrente estimado que las previsiones de la resolución combatida, en orden a someterse a las actuaciones de la Intervención General del Estado y del Tribunal de Cuentas obvian, «los órganos de control propios de que dispone la Comunidad Autónoma de Cataluña» [STC 89/2012, de 7 de mayo, FJ 9,e)]. En la resolución no se distingue, como se hiciera en las referidas SSTC 190/2000 y 98/2001, entre los controles de la Intervención General del Estado que «sólo es propio de las subvenciones que corresponda gestionar al Estado» y la fiscalización del Tribunal de Cuentas, con el resultado de asimilar ambos ámbitos de fiscalización y, en consecuencia,

34 STC 206/2001, de 22 de octubre, FJ 13.

35 SSTC 187/1988, de 17 de octubre, FJ 9 y 18/1991, de 31 de enero, FJ 3.

36 En concreto el apartado controvertido disponía como obligaciones del beneficiario: «Someterse a las actuaciones de comprobación que efectúe el órgano concedente y a las de control financiero que corresponden a la Intervención General de la Administración del Estado y a las previstas en la legislación del Tribunal de Cuentas, a quienes facilitarán cuanta información les sea requerida al efecto» (la cursiva pertenece a este trabajo). 
estimarlos invasivos de las competencias autonómicas. Bien pudiera estimarse que, a falta de ulteriores pronunciamientos, podría tratarse de un desliz susceptible de ser corregido pero, mientras tanto, pendiendo la sospecha de involución doctrinal, se estaría menoscabando la supremacía que, en el ámbito de fiscalización de las cuentas públicas ostenta el órgano nacional, por mucho que las facultades que de esa actividad se deduzcan no las ejerza en régimen de monopolio allí donde ha quedado prevista la existencia de un OCEX.

\section{B) ¿Articulación o litigio en los conflictos territoriales de fiscalización?}

Como ha podido irse comprobando a través de estas líneas. la concurrencia funcional en la fiscalización de las cuentas públicas excluye de raíz la idea de sistemas de control estrictamente separados y, por ello, se impone la articulación desde el momento en que el modelo constitucional de fiscalización de las cuentas públicas, en combinación con el progresivo desarrollo institucional del Estado autonómico, no es un modelo de separación, ni siquiera de cooperación en el sentido de reparto funcional —me refiero, aquí, a la hipótesis de un eventual reparto de sectores fiscalizados-, sino de superposición en el que el órgano nacional se encuentra, además, en una posición de supremacía. De ahí que el Tribunal Constitucional, al plantear la necesidad de la articulación, maneje expresiones como reducción a la unidad al referirse a la actuación del órgano nacional y los órganos autonómicos. Esta expresión, vertida en un sistema de superposición de controles, posibilita la existencia de técnicas de coordinación, y no sólo cooperación, que supongan, como ha declarado el Tribunal Constitucional, un cierto poder de dirección ${ }^{37}$.

La hipótesis del conflicto, sin embargo, no puede quedar descartada. No se trata, ahora, de las eventuales querellas competenciales que emergen de la ley reguladora y que se ventilan ante el Tribunal Constitucional, sino de que la concurrencia conduzca, en su caso, a la existencia de fiscalizaciones contradictorias. La contradicción podría nacer, para quien ello advierte, de una interpretación divergente del ordenamiento jurídico por parte del órgano nacional y de los órganos autonómicos, con menoscabo de los principios de unidad del ordenamiento jurídico y de seguridad jurídica ${ }^{38}$. La eventual antinomia pretende superarse mediante el recurso al conflicto constitucional de competencias entre el Estado y las CCAA, que se plantearía a través de los correspondientes órganos legislativos ${ }^{39}$, cabe

37 Sobre este particular, véase con más detalle Durán Alba, J. F.; «La aplicación de la doctrina del Tribunal Constitucional a la articulación del control externo en el Estado autonómico», Pluralismo territorial $y$ articulación del control externo de las cuentas públicas, Lex Nova, Valladolid, 2008, pp. 43-64.

38 Porras Gómez, A.-M.; La gobernanza multinivel del gasto público europeo, CEPC, Madrid, 2015, p. 234 y sg.

39 Íd. 
entender que debido a los vínculos entre los órganos fiscalizadores y las correspondientes Cámaras parlamentarias.

Dicho esto, la posibilidad de una resolución contenciosa de estas características ante el Tribunal Constitucional plantea obstáculos prácticamente insalvables. El primero de ellos - y no precisamente menor, por cierto- el de la legitimación. Si ya existe disenso doctrinal —en ausencia de praxis procesal en este sentido- a la hora de admitir la legitimación del Tribunal de Cuentas en los conflictos «horizontales» de competencias entre órganos constitucionales a partir de la críptica redacción del artículo 8.1 $\mathrm{LOTCu}^{40}$, parece imposible enervar el impedimento que supone el que la norma rituaria del Tribunal Constitucional únicamente confiera legitimación activa en los conflictos territoriales de competencias al Gobierno y a los órganos ejecutivos colegiados de las CCAA (art. 60 LOTC), sin que de la lectura del resto de normas aplicables a estas impugnaciones - o con carácter general a todos los procesos constitucionales, arts. 80 a 95 LOTC - se advierta rastro alguno que permita ampliar la legitimación establecida por la ley.

En lo que respecta a la determinación del objeto del conflicto, cumple recordar que el Tribunal lo maneja con criterio amplio pues cabe, además de la estricta invocación de la vindicatio potestatis en los supuestos en los que el recurrente reacciona ante lo que considera el despojo de la competencia que le corresponde, reivindicar «la anulación del acto o disposición objeto del conflicto porque no ha respetado el orden de competencias establecido, en menoscabo de las que corresponden al ente que promueve el conflicto» (ATC 886/1988, de 5 de julio, FJ 1). Ahora bien, aún con esta flexibilidad: ¿realmente cabe fundar las alegaciones de un conflicto constitucional de competencias en la existencia de interpretaciones divergentes de las normas fiscalizadoras; o en la existencia de solapamientos en la materia?

Ciertamente, como se ha puesto de manifiesto, la superposición de controles puede ser a priori ventajosa: incrementa el grado de control y conjura uno de los riesgos que pueden derivarse de una aplicación estricta del principio de competencia, posibilitando la existencia de zonas exentas de fiscalización al considerar cada una de las instituciones fiscalizadores que carece de atribuciones sobre las mismas. Los inconvenientes, en cambio, también existen y tienen que ver con eventuales duplicidades ${ }^{41}$. Pero, toda vez que el propio Tribunal Constitucional ha extendido las exigencias constitucionales de la economía y eficiencia que se derivan del artículo $31.2 \mathrm{CE}$, desde el ámbito de la programación y ejecución del

40 «Los conflictos que se susciten sobre las competencias o atribuciones del Tribunal de Cuentas serán resueltos por el Tribunal Constitucional». No siendo el objeto de este trabajo únicamente dejaré indicadas, a modo de muestra, las tesis, a favor, de J. García Roca (El conflicto entre órganos constitucionales, Tecnos, Madrid, 1987, pp. 68 y ss.) y, contraria, de Á. Gómez Montoro [ «Artículo 73», Comentarios a la Ley Orgánica del Tribunal Constitucional (coord. J.L. Requejo PAGés), Tribunal Constitucional y Boletín Oficial del Estado, Madrid, 2001, p. 1142].

41 Biglino, P.; «El control de cuentas: un contenido necesario de la reforma constitucional», ob. cit., p. 157 y sig. 
gasto público hasta el propio ámbito de su control ${ }^{42}$, la eventual solución de las duplicidades y contradicciones ha de resolverse desde las técnicas más propias del federalismo cooperativo que desde fórmulas contenciosas. En este sentido, viene siendo un «lugar común» la apelación al refuerzo de los instrumentos de colaboración y de coordinación propios de un «sistema, complejo, dinámico y multinivel» ${ }^{43}$ de rendición de cuentas como sin duda es el modelo español.

\section{C) El sector público local como sujeto necesariamente pasivo de la concurrencia fiscalizadora estatal y autonómica. La preservación de la autonomía local}

Tratar de aproximarse - $\mathrm{y}$ comprender - cualquier ámbito ligado a los entes locales requiere no perder de vista que se trata de una realidad sumamente compleja. En términos municipales, más de 8000 municipios con características poblacionales, organizativas y económico-financieras de singular heterogeneidad. Por su parte, la organización institucional provincial se aproxima a territorios más propios del ingenio que del genio; posiblemente resulte difícil encontrar otro ejemplo en el que, para un mismo soporte territorial quepa tal variedad institucional de gobierno. En el caso de los municipios, dicha situación podría explicar las dificultades de cumplimiento de la rendición de cuentas como paso previo para su escrutinio externo ${ }^{44}$.

No voy a detenerme en disquisiciones acerca del alcance de la autonomía local, tempranamente devaluada por el Tribunal Constitucional a las lindes de la autonomía administrativa (STC 32/1981, de 28 de julio, FJ 3), pero que seguramente se justifique en un contexto en que el Tribunal lo que trataba era de delimitar la autonomía de las CCAA más que de construir conceptualmente la autonomía local y que hoy es difícilmente sostenible, por lo menos con tal rotundidad. Descartado ab initio la eventual existencia de una fiscalización externa local propia, por el artículo 115 de la Ley 7/1985, de 2 de abril, Reguladora de las Bases del Régimen Local, que se la encomienda al Tribunal de Cuentas, el carácter bifronte de la autonomía local posibilita las relaciones directas del Estado y los entes locales — léase también la fiscalización de éstos por aquél- «sin que, en todo caso, sea imprescindible la mediación de las correspondientes Comunidades

42 STC 187/1988, de 17 de octubre, FJ 11.

43 Abellán López, Ma A.; «El sistema de control externo multinivel español: rendición de cuentas, desafíos y oportunidades», Cuadernos Manuel Giménez Abad, n 13, 2007, p. 63.

44 Análisis pormenorizados llevan, sin embargo, a conclusiones sorprendentes, así el grado de incumplimiento en la rendición de cuentas no deriva estrictamente del tamaño del municipio, como cabría esperar, pues entes locales de dimensiones considerables, que cuentan presumiblemente con mejores medios técnicos, incumplen la obligación de rendir cuentas en tiempo y forma; así, se ha señalado hasta casi la mitad de los grandes ayuntamientos [véase un completo estudio sobre este particular a cargo de FERNÁNDEZ LLERA, R. y Morán MÉndez, E.; «Presupuestos, cuentas y control externo del sector público local», Presupuesto y Gasto Público, no 89 (4/2017), p. 38]. 
Autónomas» (STC 214/1989, de 21 de diciembre, FJ 20,d) pero hace posible «a su vez, las fórmulas directas de relación y cooperación entre las Comunidades Autónomas y los entes locales» (STC 331/1993, de 12 de noviembre, FJ 3.B). Desde estos presupuestos, el sector público local, que se ha convertido en sujeto pasivo de la concurrencia funcional del Estado y de las CCAA en materia de fiscalización, fue, durante un tiempo, territorio de querellas competenciales.

La disputa por la fiscalización local llevó a recursos mutuos contra las normas correspondientes — estatal y autonómicas — que conferían el control a sus correspondientes órganos. La respuesta del Tribunal Constitucional ha sido la de asegurar la concurrencia sin que quepan exclusiones territoriales. Respecto del órgano nacional, la fiscalización del Tribunal de Cuentas puede extenderse a todo el sector público, aunque introduciendo una cautela perturbadora por la falta de precisión que entraña, la preferencia de que el control se realice preferentemente sobre el sector público estatal ${ }^{45}$, aunque más adelante afirmara que la coexistencia de fiscalizaciones se predique «sin perjuicio de la relación de supremacía establecida constitucionalmente entre el Tribunal de Cuentas y los demás órganos fiscalizadores» (STC 187/1988, de 17 de octubre, FJ 11). Respecto del correspondiente órgano autonómico, la fiscalización local se justifica porque las haciendas locales también se nutren de ingresos que provienen de la Comunidad Autónoma (STC 187/1988, de 17 de octubre, FJ 10), por ello, aunque el Estatuto de Autonomía no recogiera expresamente la facultad, las competencias estatutarias en materia local, que incluyen la tutela financiera de los entes locales radicados en el territorio de la Comunidad, permiten al legislador concretar las atribuciones del órgano autonómico de control sobre el sector público local (íd. FJ 9).

Una vez determinada que la concurrencia de fiscalizaciones sobre el sector público local garantiza la coexistencia, sin que quepan exclusiones en uno u otro sentido $^{46}$, la pregunta es cómo hacer compatible la autonomía local constitucionalmente garantizada con este sistema de control. Pues bien, no Tribunal Constitucional no sólo ha puesto el acento en que tal coexistencia no suponga una superposición ineficaz de controles ${ }^{47}$, sino en fijar una serie de parámetros que

45 «Que si bien la función fiscalizadora del Tribunal de Cuentas puede extenderse a todo el sector público, incluidas las Corporaciones locales, el ámbito principal y preferente de su ejercicio es el de la actividad financiera del Estado y del sector público estatal» (STC 187/1988, de 17 de octubre, FJ 8).

46 Ni siquiera allí donde el Estado carece de competencias de gestión, pues son de titularidad autonómica, puede negarse la intervención controladora del Estado a través del Tribunal de Cuentas fiscalizando las cuentas locales (STC 45/2017, de 27 de abril, FJ 3,d).

47 El Tribunal ha apelado expresamente al «empleo, en su caso, de las técnicas tendentes a reducir a unidad la actuación de uno y otros y a evitar duplicidades innecesarias o disfuncionalidades, que serían contrarias a los criterios de eficiencia y economía enunciados en el art. 31.2 de la Constitución» (SSTC 187/1988, de 17 de octubre, FJ 11, 214/1989, de 21 de diciembre, FJ 28, y STC 18/1991, de 31 de enero, FJ 5).

En este sentido, en el ámbito previo de la rendición de cuentas, puede destacarse la introducción por parte de la Intervención General de la Administración del Estado de un formato uniforme para la remisión de las cuentas, frutos del impulso y colaboración de Tribunal de Cuentas y de los OCEX (Fernández Llera, R. y Morán Méndez, E.; ob. cit., p. 40). 
permitan determinar que el sujeto fiscalizado no queda con respecto del sujeto fiscalizador en una situación de sumisión o subordinación jerárquica. Dichos criterios son: en primer lugar, la concreción de los controles, debiendo huirse de un sistema de control genérico e indeterminado «que sitúen a las entidades locales en una posición de subordinación o dependencia cuasijerárquica respecto de la Administración estatal o autonómica». Y en segundo lugar: que serán los propios órganos de la administración local quienes deban «entender de las propuestas» contenidas en los informes de fiscalización ${ }^{48}$.

En atención a lo expuesto y a la procedencia de la doctrina del Alto tribunal podría subsistir la duda de si esos criterios sólo son exigibles respecto de la fiscalización que, sobre los entes locales ejerzan las CCAA, o también son predican del Estado. La respuesta debe ser afirmativa, por la construcción de la doctrina, en virtud de la cual, la autonomía local garantiza queda lesionada si el sistema de controles que se arbitre coloca a los entes locales en una situación de dependencia jerárquica nace de los recursos contra la legislación local del Estado (STC 4/1981, de 2 de febrero, FJ 15.A). En refuerzo de esta tesis cabe señalar que el Tribunal Constitucional ha descartado en resoluciones recientes que la obligación legal, por parte del órgano interventor local, de remitir informes al Tribunal de Cuentas de las resoluciones adoptadas contrarias a los reparos de la intervención pueda considerarse un control político; para el tribunal, en rigor, los controles ya están establecidos y delimitados legalmente, tratándose los informes controvertidos, más bien, de una técnica de colaboración interorgánica para que la fiscalización sea efectiva ${ }^{49}$.

A lo largo del presente apartado ha podido comprobarse cómo la intervención del Tribunal Constitucional en la determinación de los que podría denominarse «fiscalización territorializada» de las cuentas públicas no resulta especialmente problemática. Los problemas apuntados tienen que ver, más bien, con la precisión de la doctrina. En este sentido, además de esperar ulteriores matices a la STC 89/2012, de 19 de mayo, considero que al Tribunal le queda construir de forma más acabada en términos constitucionales el significado de la supremacía que el artículo $136 \mathrm{CE}$ atribuye al Tribunal de Cuentas pues la reiterada contraposición la misma y las apelaciones a que el órgano nacional, de forma preferente, intervenga en el ámbito estatal permiten interrogarse si el correcto deslinde de esa intervención puede ser contralado, por quién y cómo ${ }^{50}$.

48 STC 187/1988, de 17 de octubre, FJ 10.

49 STC 44/2017, de 27 de abril, FJ 4 (doctrina reiterada por la STC 93/2017, de 6 de julio, FJ 5).

50 Ese impreciso equilibrio, afirmado desde antiguo, entre supremacía y autocontención puede advertirse, una vez más en la sentencia sobre el Estatut de Cataluña cuando el Tribunal afirma que: «el art. 80.1 EAC no excluye ni impide que el Tribunal de Cuentas, en tanto que 'supremo órgano fiscalizador de las cuentas y de la gestión económica del Estado, así como del sector público’ (art. 136.1 CE), pueda fiscalizar las cuentas de la Generalitat, de los entes locales y del sector público de Cataluña, manteniendo la relación de supremacía que ex Constitutione le corresponde sobre los órganos fiscalizadores de las CCAA, si bien hemos precisado también que el ámbito principal y preferente del ejercicio de su función fiscalizadora 'es la actividad 
TITLE: What has to be done with the control of public finances?

AвSTRACT: Our model of audit of public finances was established by the Constitution and inferior norms decades ago. However, the system presents some endemic problems which derive from its highly decentralized character. Some of these difficulties came from the norms which rule on the institutional position, compositions and functions of the several organs that exercise the control. However, other defects come from the adverse practices generated by the application of the logic of the "State of political parties" to the external control of public finances. Furthermore, the article stresses that some statements of the Constitutional Court should be reconsidered.

Resumen: A pesar del tiempo transcurrido desde la puesta en funcionamiento del modelo de fiscalización externa de las cuentas públicas, previsto por nuestra Constitución y normas de desarrollo, subsisten problemas —casi endémicos - que dificultan la correcta articulación de un sistema de control fuertemente descentralizado. Algunos elementos disfuncionales se encuentran, desde luego, en el régimen jurídico que disciplina la posición institucional, composición y marco funcional de estos órganos. Pero no pueden dejar de apuntarse las perniciosas prácticas a que ha conducido a veces el traslado de la lógica del estado de partidos al ámbito de control externo de las cuentas públicas. Por su parte, también se advierten en las resoluciones del Tribunal Constitucional algunos pronunciamientos que sería necesario modular.

KeY words: Public Accounts, Budget, Public auditing, Liability, Decentralization.

Palabras Clave: Cuentas públicas, presupuesto, fiscalización, responsabilidad, descentralización.

FECHA DE RECEPCIÓN: 14.01.2018

FECHA DE ACEPTACIÓN: 08.02.2018

financiera del Estado y del sector público estatal' (STC 187/1988, de 17 de octubre, FJ 8)» (STC 31/2010, de 28 de junio, FJ 34). 